KAROLINA KUBERSKA

University of St Andrews

\title{
Sobreparto and the lonely childbirth: Postpartum illness and embodiment of emotions among Andean migrants in Santa Cruz de la Sierra, Bolivia
}

\section{Introduction}

$\mathrm{P}$ regnancy, childbirth, and the postpartum period have received considerable attention in ethnographies of the Andean region. Although they are usually analysed through the lens of traditional Andean understandings of the body, health, and illness (e.g. Loza \& Álvarez 2011; Larme \& Leatherman 2003; Bradby \& Murphy-Lawless 2002), or, occasionally, mytho-history (Platt 2002), it is also analytically worthwhile to foreground the social dimension of these phenomena. Narratives on pregnancy and childbirth among Andean migrants in a lowland Bolivian city reveal the importance of social support during those moments of life. These individual accounts highlight a strong correlation between a perceived loneliness during childbirth and the postpartum period as well as a traditionally Andean postpartum condition known as sobreparto. In this paper, I would like to focus on childbirth and sobreparto in the light of the remembered emotional trajectories of these events among Andean migrants in Santa Cruz de la Sierra. While it is clear that sobreparto can be analysed in categories of health and illness, it is especially productive to consider it as a lens for wider, non-medical processes at work in migrant women's lives, such as motherhood and womanhood, emotions and sociality, or the biomedicalisation of pregnancy and childbirth.

Sobreparto is a potentially dangerous postpartum condition that typically occurs in the Andes. The available ethnographic data on sobreparto suggest that women who do not observe postpartum rules, such as staying warm, not touching water, avoiding exposure to cold air or winds, or eating appropriate foods risk falling ill with sobreparto (e.g. Loza \& Álvarez 2011; Larme \& Leatherman 2003; Bradby \& Murphy-Lawless 2002). With its symptoms of chills, cold sweats, fever, and general weakness, sobreparto can render a woman temporarily unable to take care of her newborn baby. The traditional cure involves drinking hot herbal infusions and massaging the body with fat. Left untreated, sobreparto can have 
permanent consequences in the form of chronic debility or proneness to all kinds of ailments. Sobreparto usually occurs during the puerperium, a vulnerable point in a woman's life that goes beyond the physical strain of childbirth. Significantly, it is also a time when a woman might like to rely on her social network, which may be more difficult if one is a migrant in a large city.

Central to the understanding of sobreparto proposed here is an analysis of this postpartum condition with respect to the social world. In their research on health and illness in Delhi, India, Veena Das and Ranendra K. Das focused on "the relation between failure in the body to failures in one's social world" (2007: 69), and it is useful to apply this approach to the context of reproduction in a lowland Bolivian city. While pregnancy is not explicitly considered to be a medical condition in Santa $\mathrm{Cruz}^{1}$, women are encouraged to have antenatal checks as well as to give birth in biomedical hospitals or clinics. This, in turn, situates the processes of pregnancy and childbirth closer to biomedical understandings of health and illness. At the same time, most accounts of sobreparto I heard featured a motif of a woman who was unable to rely on the help of the members of her household, including her closest relatives. Narratives of this postpartum condition revealed material and emotional instabilities underpinning the lives of these female migrants.

This paper is concerned with understanding how reproduction and loneliness intersect in the shape of a postpartum illness known as sobreparto, which befalls migrant Andean women in the lowland Bolivian city of Santa Cruz de la Sierra. This postpartum condition embodies the hardships of women's fates but also implicitly symbolises perseverance and the importance of other people in one's life. While narrating their individual experiences of sobreparto, female migrants in Santa Cruz pointed to aspects of women's lives beyond the episodes of illness, revealing the complex landscapes of their everyday existence. On the one hand, it is possible to look at sobreparto at the micro-level - in terms of an understanding of the body, individual reproductive histories, or the availability of support from other people. On the other hand, sobreparto also constitutes a commentary on phenomena occurring at the macro-level, such as large-scale internal migration in Bolivia or the increasing domination of biomedicine as a model of health and illness (Tapias 2015). However, by pointing to what is important in these women's lives (Kleinman 1992, 2006), migrant women's narratives of this illness demonstrate how these micro- and macro-level processes become connected to each other through episodes of sobreparto.

\footnotetext{
${ }^{1}$ However, pregnant women are described in Quechua as mana sanuchu (not healthy) or unqus$q a$ (ill). The root of that latter word, unqu, points to a bodily disequilibrium (Platt 2002: 132).
} 


\section{Methodology: Intimate memories and treasured pasts}

The ethnographic research that this paper draws on was conducted in semi-urban zones of Santa Cruz de la Sierra between March 2012 and May 2013. I focused on registering women's life stories that included sobreparto, making sure that data on women's experiences of ailments following childbirth contained longer timelines and details beyond the somatic symptoms. Even with my main interest centred on sobreparto, I understood that it was important to collect entire life histories through multiple and repetitive conversations with a number of women. This decision was motivated by my desire to be able to reconstruct detailed life stories whose chronologies I verified in subsequent conversations. Additionally, positioning the illness within the context of events preceding labour, as well as following it, allowed more memories to surface. By extending the scope of my interests I was able to gain insight not only into the illness, but also many more subtle changes about women's attitudes towards their consecutive pregnancies.

I did not witness an episode of sobreparto during my fieldwork, neither did I seek to observe one when I was planning the research. While I experienced some of the unsatisfied curiosity of a researcher who has to rely on second-hand accounts, I must also admit that I was relieved that none of my informants who had given birth during my fieldwork experienced a bout of sobreparto. As a result, my fieldwork data relies on narratives of individual experiences of that illness as told by Andean migrant women who were fortunate enough to recover. This limitation influenced the kind of information I had access to, but, at the same time, opened up different interpretative avenues of sobreparto, locating it within the time frame of the entire pregnancy and postpartum (or beyond), and linking it to emotions experienced during that period.

\section{Santa Cruz de la Sierra, migrants, and medical pluralism}

The lowland Bolivian city of Santa Cruz de la Sierra may not be the first choice for the study of a phenomenon typical of the Andean zone. However, the last sixty years of population growth in Santa Cruz were significantly fuelled by incomers from Western Bolivia, who compose a diverse population of Andean migrants. While it is possible to come across migrants from the Andes everywhere in the city of Santa Cruz, many of them live in marginally located zones, such as Plan 3000 , where I conducted my fieldwork. In addition to their own ways of living, Andean migrants also brought new ways of healing. As a result, both traditional Andean healers and illnesses have secured their place in the lives of Santa Cruz inhabitants. Some of the largest markets have entire sections dedicated to traditional Andean medicines, and almost every local market has at least a few small stalls with herbs and incenses for everyday ailments. This situation is made even more complex - and particularly interesting - by the ostensible dominance of biomedicine in Santa Cruz, embodying the city's (and country's) claims 
to progress and modernity. Formally, these strategies were legally ensured by the Bolivian Constitution from 2009, which recognises all medical systems as equal, as well as official government structures, such as the Vice-Ministry of Traditional Medicine and Interculturality. At the same time, many pregnant women (and their children) have access to government-funded universal biomedical healthcare cover called SUMI (Seguro Universal Materno-Infantil, Universal Mother-Infant Insurance) (Galindo Soza 2010). Given this context, it is particularly interesting that Andean migrants in Santa Cruz unanimously say that biomedical doctors do not know how to cure sobreparto.

There are multiple dimensions of the significance of sobreparto in women's lives. It is almost intuitive to categorise it as an illness - especially bearing in mind how sobreparto is usually presented with reference to competing traditional and scientific/biomedical systems. Furthermore, the biomedical point of view, encouraged by free, state-offered health services and the proliferation of private biomedical clinics, promotes an understanding of a patient as an individual (rather than as part of a reciprocal social network) who is largely, if not explicitly, responsible for their condition, then at least for making attempts at getting better (by using biomedical services). This makes it even more complicated to remove sobreparto from the discourse of aetiologies, symptoms, and diagnoses and to position it as a life event, which is strongly intertwined with the local social network, the importance of reciprocity, and the intentional testing of one's own capacities. Emphasising the social dimension of this postpartum condition has been addressed in the ethnographies of the Andean zone (e.g. Larme \& Leatherman 2003), where biomedical interventions surrounding childbirth did not tend to be taken for granted (e.g. Bradby 1999). I would like to argue that interpreting sobreparto as a life event may shed new light on the social dynamics of sobreparto among Andean migrants in Santa Cruz de la Sierra. In fact, looking at this condition as a situation in which social networks are tested - not just by and for the woman, but also by and for others - offers insights into people's lives without reducing their bodies to medical objects.

\section{Reciprocity, biomedicine, and well-being}

In order to better understand the relationship between the postpartum illness in question and the position of a woman who has just given birth within the bounds of her social network, it is necessary to look at the way in which the concept of the body has traditionally been constructed in the Andes. It was clear during my fieldwork that there were few - if any - Andean migrants in Santa Cruz whose understanding of how the body functions did not include at least some elements of the biomedical model. At the same time, an analytical separation of these understandings may offer an insight into medical conditions falling beyond the scope of biomedicine, such as sobreparto, illnesses whose aetiologies are not restricted to individual bodies. 
According to ethnographic literature, an Andean body is a manifestation of a balance between humanity, the environment, and the spiritual world (Bastien 1978, 1987; Allen 1982). There is a web of reciprocal duties, which connects people, spirits, mountains, earth, and stars. These mutual obligations are fundamental to well-being and are satisfied with acts of reciprocity, which characterise traditional Andean social relations (see e.g. Miles \& Leatherman 2003; Tousignant 1989). The corollary of understanding the body as interrelated with other bodies and elements of the landscape is that reciprocity - and following other social rules concerning other people, the spiritual world, and the landscape - ensures health and protects from illness. On the other hand, a disruption of the social harmony or a transgression of accepted rules, for instance through the refusal of communal duties or the expression of negative emotions, exposes the body to a reprimand from the spiritual world, often in the form of illness (Cooley 2008: 138-139; Greenway 1998, Larme 1998). While the occurrence of rules of reciprocity is by no means confined to highland Bolivia, Andean migrants in Santa Cruz may struggle while trying to satisfy the requirements of such interchanges due to the pressures of living in a large city.

The social networks of Andean migrants to Santa Cruz de la Sierra are frequently weakened as a result of relocation, especially in the initial phase of migration. While family networks usually remain very important sources of support, and are actively acknowledged through visits, phone calls, and family gatherings, the demands of city life (such as the time spent working and commuting) limit the amount of time, energy, and enthusiasm that people are able or willing to devote to this part of their lives. Most of the women who spoke to me had relatively intensive contacts with their closest neighbours, co-workers, or vendors in adjacent stalls at the markets, although these relationships were rarely able to match the strength of kinship ties. Within the household where I lived during fieldwork, mutual help between family members was both intensive and generously dispensed: my landlady Doña Paula's daughters and her daughter-in-law assisted in the shop, her partner, Don Pedro, accompanied her in the early mornings to the markets to restock supplies, and hardly did anyone ever refuse to take care of baby Raquel for hours on end. While helping each other was constant, it did not remain unquestioned: sometimes comments were made about giving or accepting more than necessary, or taking advantage of a situation. For instance, it was acknowledged that Rosa and Roberto, who both had jobs, had the right to ask someone to take care of Raquel when they were both at work at the same time (Roberto, a medical student, was then in his last year at university and also had a part-time job while Rosa worked as a nurse). However, when they asked Silvia, Roberto's sister, to babysit Raquel when they wanted to go out for dinner with friends for the second time since their 11-month-old daughter was born, the request was met with fierce opposition. It is interesting that it was Rosa (rather than the couple, or Roberto himself) who decided that they did not have the right to insist on this kind of help, a favour rather than a real necessity, from immediate family members, who were Roberto's blood relatives. In the end, Rosa asked me 
(at that point I had only been living with them for three and a half months) and I happily agreed, but I heard some comments about my decision which were directed towards Rosa and Roberto who apparently were disfrutándose demasiado, having too much fun, and aprovechándose de mi, taking advantage of me.

An interesting difference in attitude could be observed in situations when Sara, Doña Paula's distant niece, visited the household. She was always accompanied by Lucía, her three-year-old daughter. Initially, they would stay for an afternoon but then Sara began to drop Lucía off for several hours, without informing anyone when she would be back. Because Sara never really explained why she needed somebody else to take care of Lucía, Doña Paula and Rosa inferred that she probably had some business to take care of and lugging her fussy daughter along through the city offices would slow everything down. Although this speculative explanation might have been considered probable, Rosa once said: Pero eso ya es abusivo, de Doña Paula y de la niña, but this is already abusive, of Doña Paula and the girl. It is interesting that she left herself out of this situation of "abuse," despite the fact that she would usually undertake some of the activities related to caring for Lucía, such as feeding her, offering her a jacket when it got chilly in the evening and sometimes putting her down for an afternoon nap. Still, Doña Paula and Rosa had little enthusiasm for taking care of Lucía, which made them complain to me about Sara's behaviour. For instance, they would say to me that they too were busy but did not resort to dropping Raquel off with other relatives (i.e. not her main caretakers). I never witnessed a direct confrontation between Doña Paula, Rosa, and Sara, and the most aggressive phrase I heard (although I was not always present when Sara finally returned to pick up her daughter) was when Rosa said to her: su hija le estrañaba, your daughter missed you ${ }^{2}$. In general, it seemed to me that although reciprocity and family obligations are readily recognised aspects of social life, there are often perceived difficulties with satisfying these demands on a daily basis.

Living in a city such as Santa Cruz may contribute to the notion that doing favours, such as those described above, is rather troublesome. In other words, helping each other in everyday activities is not taken for granted beyond the closest family and friends. However, there is another factor undermining the importance of reciprocity, traditionally understood as ensuring personal and community well-being. The validity of such a positioning of reciprocity in social life is challenged by the increasing presence of biomedicalised notions of health and illness in Santa Cruz, which do not take reciprocity as a factor of well-being into account. Moreover, while biomedicalised understandings are readily combined with traditional understandings, certain fundamental contradictions remain. One of the

2 This translation does not (and cannot) reflect the use of the polite - or distancing - form of address, Usted ( $U d$.) (3rd person singular). $U d$. is often used synonymously with tú (2nd person singular, equivalent to the singular "you" in English) in Bolivia. In fact, $U d$. is acceptable between spouses or friends (and not just strangers) when politeness is an important aspect of the interaction. In this situation, the use of $U d$. by Rosa implies social distance, unwarranted between affines and women of similar age. 
fundamental contradictions between biomedicine and traditional medical systems is the individualisation of the patient favoured by the former. In other words, while the quality of interpersonal relationships is sometimes recognised as a factor in the healing process, it is hardly ever understood as a cause of an illness in and of itself.

There are two general tendencies which feed into each other in the process of transforming the way in which health and illness are conceptualised by migrants from the Andes to Santa Cruz. On the one hand, people frequently believe in both non-biomedical and biomedical explanations in roughly equal measure but they also recognise that some medical systems deal better with certain conditions than others. For instance, there was a common consensus among my informants that biomedicine does not know how to cure sobreparto ${ }^{3}$, but that it is able to deal with certain conditions which require surgical solutions, such as appendicitis or a complicated delivery. On the other hand, the authority of scientific biomedicine increases due to the privileged support it receives from the Bolivian government, not just through legislation, but also through informational campaigns in the media or developments of health infrastructure, such as constructing new hospitals. In other words, people's knowledge about the fallibility of biomedicine makes them aware of its inability to cure every medical problem; nonetheless, its strong presence in everyday life normalises it as the first resource when it comes to issues of health and illness.

In this respect, Andean migrants in Santa Cruz experience two kinds of tensions. First, they find themselves torn between the demands of the city life and the importance of mutual help and support in the community network. Second, they experience the contradiction situated in considerably different ideas of health: one that is a matter of social harmony, achieved through reciprocity among other factors, and another, in which health is, to a large extent, dependent on individual choices or misfortunes, as biomedical science would like to have it. In this context, it is interesting to look at the occurrence of sobreparto among Andean migrants in Santa Cruz de la Sierra as an attempt to bridge these tensions while maintaining their highlander identity.

\section{Loneliness, embodiment, and postpartum illness}

The case studies collected during my fieldwork consist of accounts of women who migrated to Santa Cruz de la Sierra from the Andean zone in Bolivia and who fell ill with as well as recovered from sobreparto. I argue that the condition of migration, with its inherently reduced social network, may accentuate the precariousness of women's circumstances, especially the feeling of loneliness, and make sobreparto more likely on the one hand, and more significant, on the other

3 This conviction is also common in the Andes, see e.g. Loza \& Álvarez (2011); Larme \& Leatherman (2003); Bradby \& Murphy-Lawless (2002). 
(Loza \& Álvarez 2011). In fact, in the urban context of Santa Cruz, women I interviewed spoke of loneliness as much as their bodily experiences. The account of sobreparto, as told by Doña María, will hopefully illuminate the complexity embedded in reproductive life, beyond the postpartum illness.

\section{Doña María}

I had seen Doña María many times before we properly met. She had a small stand, selling home-made empanadas, fried dumplings, filled with cheese or meat, and refresco, sweet drink made from fruit juice, such as lime or passion fruit, iced water, and copious amounts of sugar. I would stop by her stand more often to talk while sipping the cold sweet drink she sold. Even though I told Doña María that the reason I was living in Santa Cruz was because I was interested in understanding sobreparto, it was only a couple of months after our first encounter that she confessed to me that it had happened to her. It felt like she had decided it was time I asked her about her story.

Doña María, now in her fifties, came to Montero, a town close to the capital of Santa Cruz, from Chapare in Cochabamba department, when she was only fifteen. She met her first husband there and had her first three children with him, all boys. The couple divorced and Doña María became pregnant by another man, who left her a year after their daughter was born. Armed with willpower and Pentecostal faith, Doña María worked very hard to make a living and provide for her four children. Several years later, she began a relationship with a new partner and became pregnant again. The new man was gone before the baby Laura was born. Doña María saved money to give birth in a private clinic. She proudly said:

All my children but the first one were born in a clinic - with the first one, they didn't take care of me well in hospital, so I didn't go back there, I didn't want to risk that they treat me badly. For example, with the second son, he didn't want to come out, he was born after ten months and ten days and weighed 5800 grams, but I gave birth the normal way, the normal way. They wanted to operate on me, but I didn't want them to operate on me. But in a clinic, I could decide, I could tell them: No, I don't want surgery [C-section]. So they didn't operate.

I asked what happened after Laura was born.

They didn't operate either. But it was different that time. ¡Ay, me puse mal! Oh, I got so ill! When my daughter was born, Laura, the one that weighed 3800 grams, then, it was then that I fell ill with sobreparto. Because when I give birth, I don't like [to stay in] bed! I just don't like it. I am a hard-working woman. Any other day, any other day I can go home tired, I lie down, I sleep, but on the day when I give birth to a baby, it seems like my blood smells bad, I feel... I don't know.

She paused for a good minute. 
Well, I take a shower immediately, I wash myself, I start cleaning myself. My relatives were saying: "You're gonna get sobreparto, este sobreparto duele feo ${ }^{4}$, this sobreparto hurts like hell, it's worse than childbirth," but I didn't listen to them at all. I would tell them: "You are lazy, dirty, how can you stay in bed, lazybones, lying down all day!" But the day when I fell ill with sobreparto I understood it, I understood that they were right.

It went like this - Doña María stopped to take a deep breath - I left the clinic as usual - normally they make you stay for 3 days but I went home on the same day, the same day when Laura was born. So my daughter was born at a quarter past five in the afternoon and I was ready to go home by eight or nine o'clock. I told the doctor that I knew what was going on, it's a familiar situation, so they didn't keep me in the clinic.

The next morning I started doing what I normally did - I began cleaning myself, the whole house, I cleaned everything, I did not stay in bed, oh no! Then I washed myself, I had a shower, but around 10 a.m., or maybe around noon, I started feeling escalorfrío, chills and shivers, they would not stop. "Oh, - I was asking myself - what's going on with me?" I was having escalorfrío, a lot of escalorfrío. My spine hurt again, this part - she placed the palm of her hand on the lumbar curve - my bones hurt. And it [the pain] wasn't going away, and it wasn't going away. And it was a strong pain, very strong. But it was like when the labour's coming, you know, the labour pains, it would hurt like this, stronger, and stronger, and stronger, until I couldn't bear it anymore... Like contractions, although nothing was coming out, there was only the bone pain. How can I explain it to you? - Doña María looked at me quizzically - I didn't understand it myself at the time.

My head hurt but the bones hurt even more, it was as if I was being squeezed or crushed, as if I was being wrung, everything hurt, I thought I was going mad, I couldn't stand it any longer, I was shouting and shouting, my teeth, my teeth were chattering from the cold, I didn't understand, I cried and cried because it was unbearable, from here - Doña María pointed to the top of her head - to here she bent to reach the tip of her big toe with her finger - There was pain in my head and in my bones, and inside me. And because I didn't know, I drank water and I took novalgina ${ }^{5}$, because back then there was novalgina, so I bought myself one pill of novalgina ${ }^{6}$, but one lady said: "No, Doña María, no..." And I felt cold and the escalorfrío, but she said "That's not what really hurts, that's not it," she said. "You are having sobreparto," she said. That's what she called it: sobreparto, "Because you are not taking care of yourself!" the lady scolded me.

I asked if that lady was a healer. Doña María quickly said:

No, no, she wasn't. They say that she had this illness, sobreparto, this is why she knew what to do. ¡Jovencita! She was so young! She would tell me: "The doctors don't know it, they had no idea how to cure it when I got it the first time!" It was she [the young girl], she said, that she got ill with it, and this is how she knew what to buy and what to do.

4 Lit. it hurts ugly.

5 A type of analgesic, antipyretic, and anti-inflammatory medication.

${ }^{6}$ It is common in Bolivia to buy medication per pill rather than the entire packet. 
She came to my house and rubbed my whole body with Mentisán, even the head, she rubbed the head well, and also, she brought all kinds of stuff, they sell it in the market, you know, I don't know what it was exactly but they sell it in the market. El sahumerio, an incense, I think. She did something like this: she lit the incense mixture on fire and when it was burning, she fumigated me with it, she waved it over me, she covered me with a thick blanket, she told me to lie down on my bed again, and then she scraped my nails.

Doña María saw my puzzled look, took a small vegetable knife and scraped the surface of my thumb nail with the sharp edge, muttering softly as the blade glided over my nail: „Así, así no más. Like this, just like this”. Tiny scrapings of my nail fell to the ground.

She made a small fire in the room with all kinds of herbs and something else that they sell here - but I don't know what it was. She took a burning twig and held it in her hand, like this -

Doña María extended her right arm in front of her, holding the imaginary twig at the level of her knees.

And she made me stand above it, with my legs spread apart, and she moved it [the burning twig], here, so that it enters the womb, so that all this smoke is absorbed.

Doña María was standing now, her legs apart, her hands moving her skirt energetically to direct the imaginary smoke towards her womb.

Then she rubbed my head towards the back. They [women who heal] know. And then she grabbed me and put me down on my bed and covered me with the same thick blanket. Then she scraped my nails.

I asked if the lady used a knife. Doña María shook her head.

No, con vidriecito, with a piece of glass, she did it with a piece of glass and I heard her saying, she was saying: you have to toast half of it [the nail scrapings] and leave the other half untoasted. Then she took a bit of my hair from here - Doña María touched a small area behind the left ear - my own hair. Then she sent to buy somebody's nails, I don't remember - no, I do, I remember, it was pig's hoof ${ }^{7}$.

As I was feeling very bad, I just heard her sending someone to buy those things, I think maybe she sent my son to do it. And they did it as well, they did all that, they made an infusion of all those things. And they made me drink it calientito, hot! She told me not to get up, they put socks on my feet, they put a jumper on me, they put... They bound my head, my hair, all that. Since then I stopped getting up from bed to do things [after childbirth], I started being afraid. This is how, this is how I had my sobreparto, what they say it is.

\footnotetext{
7 In Spanish, the words for nail and hoof are similar, uña and pezuña respectively, hence, Doña Carmen could categorise hoof, pezuña, as some kind of nail, uña.
} 
I asked how long the treatment took.

Since noon, I cried for three hours. But they cured me fast, very fast. I slept well that night, I was already healthy. They cured me fast because... It's good to live here, you know, people help you, there were lots of neighbours, so I didn't live alone, I didn't have to live alone. When I got pregnant again, I was afraid about it. I left the hospital, I showered and I would buy rosemary, my aunts were telling me about it, that you have to wash yourself with rosemary [infusion] before washing yourself with water that isn't pure. So I washed myself with rosemary infusion, hot rosemary infusion. Because I was afraid.

Doña María looked me in the eyes and repeated under her breath: „I was afraid.”

In her narrative, Doña María positions herself as a single mother, a woman on her own, who can - and, more importantly, must - primarily rely on herself, and for whom this strength and independence are a source of pride. These features of her personality seem to be the reason for her emphasis on the speed with which she recuperated from her bout of illness. What is interesting in her story is a crucial absence of a husband (or husband-like partners) beyond what can be deduced from the fact that she became pregnant a number of times. This image is contrasted with other people supporting Doña María in her time of need - and she is explicit in appreciating the value of a tight-knit community in the neighbourhood. Before she suffered an episode of sobreparto, her indirect knowledge of this condition was based on her relatives' critical comments about her reluctance to observe traditional postpartum proscriptions. Nonetheless, when she became ill, it was other people (rather than her absent husband) who came to the rescue and I argue that the demonstration of the reliability of the social network is no less important than the appropriate cure. In the absence of a life partner, it was the community she joined and co-created as a migrant in Santa Cruz that proved to be able to offer help and support. These motifs appear in other life stories I collected in various combinations, revealing the complicated landscape of issues accompanying bouts of sobreparto, exposing the inadequacy of interpreting it as an illness.

\section{Caring about the body: Perils of the postnatal period}

In such a context, pregnancy leads something of a double life. In the shadow of biomedicine, there are restrictions concerning the postpartum period, which reflect traditional understandings of the body in multiple ways ${ }^{8}$. In the Andes the postpartum body is traditionally considered to be open. This female openness is due to the additional orifice, the vagina, which is seen as a channel through which

8 The information in this paragraph has been compiled from the following sources: Loza \& Álvarez (2011); Bradby \& Murphy-Lawless (2002); Arnold, De Dios Yapita et al. (2002); Arnold, Murphy-Lawless et al. (2001); Yon Leau (2000); Leatherman (1998); Larme (1993, 1998); Luerssen (1993); Gonzales et al. (1991); Lira (1985); Plath (1981); and Frisancho Pineda (1973). This summary focuses on elements which occur in multiple ethnographic accounts. 
illnesses may find their way in (see e.g. Cooley 2008: 141; Bradby \& Murphy-Lawless 2002: 46-47). Childbirth, accompanied by the loss of blood, leading to a certain level of bodily disequilibrium, exposes the woman to additional dangers, such as wayras, illnesses carried by cold, malevolent winds (Larme 1998; Platt 2002). The woman should be kept warm both during and after childbirth, which is achieved by heating the room in which labour takes place as well as covering her with thick blankets. Exposure to cold air, winds, or even excessive exposure to sun should be avoided. The heat must also be maintained through appropriate nutrition; various kinds of broths (e.g. mutton or chicken) and other foods considered hot, aid in restoring bodily equilibrium.

Conversely, foods categorised as "cold" are prohibited - these, depending on the region, may include: ají (spicy condiment), onions, potatoes, plantains, papaya, etc. Furthermore, contact with water (especially cold water) is explicitly stated to be dangerous: my informants commonly referred to it as no hurgar/agarrar/tocar agua, not to poke [one's fingers in]/hold on to/touch water. This restriction requires the woman to refrain from taking showers (although she can wash her body with a cloth soaked in a warm herbal infusion, with rosemary as the herb most often mentioned) as well as doing the laundry. The first prohibition requires a lot of willpower in the sultry Santa Cruz summers, when almost everyone showers at least a couple of times a day ${ }^{9}$. What makes the second prohibition difficult to observe for prolonged periods of time, in addition to the speed with which babies are able to generate dirty clothes, is the fact that it is specifically women who are expected to hand wash the laundry ${ }^{10}$. In fact, doing the laundry was amongst the most common causes of sobreparto mentioned by migrant women in Santa Cruz in our conversations about this condition.

Ethnographic data collected in various parts of the Andes generally contends that once the placenta is delivered, it should be inspected for missing pieces (which is indicative of complications, such as postpartum haemorrhage). If it is expelled in its entirety, it should be buried or burnt - which will prevent the baby from developing infections (Bradby 2002: 183; Platt 2002: 133, 144; Murphy-Law-

\footnotetext{
9 Some of the research participants expressed ideas about the danger of showering too often, irrespective of weather. One said that even though the water in Santa Cruz seems warm, it is not truly warm. According to her, frequent showers could lead to arthritis in future. When I told her that the baby living in my house was bathed two or three times a day during heat waves, she commented that this baby would be sick a lot in future due to excessive exposure to the coldness in the water.

${ }^{10}$ One of my research participants has a husband who is willing to do their family laundry to help her out - however, he always hangs a large sheet next to the laundry sinks so as to conceal his activity from people in the street, which he fears would be detrimental to his macho reputation. While some studies in the Andean zone document occasions in which men are likely to help their partners in times of need, including situations related to parenting (see e.g. Platt 2013; Dibbits 2003), there is a very strong macho ethos in Santa Cruz, to which migrants sometimes gravitate, which in turn influences their intimate relationships.
} 
less 1998: 5-6; Gonzales et al. 1991: 26) ${ }^{11}$. Contemporary Bolivian "intercultural health" regulations concerning childbirth recognise the existence of local understandings of the significances of the placenta for certain indigenous groups in the country (Galindo Soza 2010: 164-165; Ministerio de Salud y Deportes 2006); however, in practice, it is still the prerogative of particular hospitals to comply with their patients' demands (Rubén Vaca Vaca 2013, personal communication). When I asked migrant women in Santa Cruz about it, they talked about a wide range of experiences: some claimed that it is disgusting and muy del campo, very much countryside-like, others did not even know about this custom. There were women who asked for, received, and buried their baby's placenta, but also others who complied with the tradition with their first couple of children and abandoned it with the following births. Finally, some migrants were given the placenta without requesting it, and it was thrown out with other rubbish. Based on the data I collected, it is clear that there is knowledge about the traditional significance of the placenta, however, it is becoming increasingly less common for migrants to follow Andean customs concerning its disposal.

The transformations of ways of handling the afterbirth reveal considerable influences of rationalism, understood as science-based knowledge and reasoning, fuelled by biomedical sciences. From the point of view of biomedicine, the role of the human placenta ends abruptly once the foetus leaves the uterus (see e.g. Hrdy 1999). While it is very important that the placenta is expelled in its entirety or that measures are taken to clean its fragments from the uterus, once it is out, it becomes medical waste. Some hospitals in Santa Cruz do just that, irrespective of the government's intercultural health regulations concerning other medical traditions ${ }^{12}$. Most healthcare facilities in Santa Cruz, however, are willing to accommodate requests for the placenta although it is significant that these requests are frequently considered to be non-standard, especially outside of impoverished neighbourhoods. This further reinforces the dominance of the biomedical stance with respect to how this aspect of childbirth is viewed both by Andean migrants in Santa Cruz and by the remainder of the city's population.

\footnotetext{
11 There is, however, ethnographic evidence that incorrect handling of the placenta may influence the mother. For instance, Platt (2002) documents a belief in q'ara wawas (Qu. naked babies), predatory spirits or goblins in Macha, Potosí, Bolivia, which emerge from a placenta which was not disposed of in a correct manner or aborted foetuses. "Without the Christian salt of baptism, [buried aborted foetus or unbaptised placenta] grow into a 'naked baby' ([Qu.] q'ara wawa or q'ara uña) or 'goblin' ([Qu.] twinti, Sp. duende), which kills its mother by returning to eat blood in the womb and continuing to eat until it consumes the heart ([Qu.] kurasun, Sp. corazón)" (Platt 1997). Similar beliefs have been documented for other areas in Latin America (see e.g. Morgan 1997).

12 Based on my conversations with migrant women from different social classes, private clinics tend to disregard any traditional manners of disposing of the placenta as superstition. On the other hand, both private and public health institutions in Plan 3000, where a large part of the population is of Andean origin, readily accommodated people's requests for the afterbirth (or simply handed the placenta to the families without asking whether or not they wanted it).
} 
While proscriptions concerning the afterbirth may have been losing their significance for the migrants in Santa Cruz de la Sierra, as evidenced in Doña María's narrative, the belief that the puerperal female body should be bound in a certain way remains very strong. Despite the fact that women I spoke to were often aware of the difference between the practice and the rules, they usually had a considerable degree of clarity as to what should be done regarding the postpartum binding of various body parts. Firstly, it is generally advisable that the head remains covered with some kind of a headscarf or a hat to protect it from exposure to the cold, wind, or sun (although my informants in Santa Cruz often confessed to not following this rule too scrupulously ${ }^{13}$ ). Secondly - and more importantly - the abdomen should be bound for a period following childbirth (my informants suggested periods between a month and six months as ideal) in order to prevent a variety of ailments related to the shifting of internal organs.

There are differences regarding the item used to bind the abdomen, although it tends to be referred to as a faja. It could be a thin, woven strap, in which case its primary function is stopping the womb from moving upwards in the body and asphyxiating the woman; ${ }^{14}$ alternatively, it could be a large square piece of fabric, folded diagonally in half to form a triangle, wrapped two or three times around the woman's abdomen. These latter kinds of fajas in Santa Cruz were also said to keep the loose skin tighter and to help restore the pre-pregnancy figure. Many women who spoke to me would attribute or explain the presence of abdominal fat (in themselves and other women) to not having bound their abdomens with fajas in this crucial postpartum period or not having done it for an appropriate length of time. A few of my younger informants used a modern version of faja in the form of shapewear, a cross between a one-piece swimsuit and underwear, made of elastic fabric in colours typical of lingerie. Some of my research participants explained that faja alleviates the pain felt during the re-acomodación de los órganos, the movement of the internal organs during the postpartum, when the uterus is shrinking and the organs, can, as one of my informants phrased it, "finally go back to their right places". In any case, it seems that the binding of the abdomen remained a more observed postpartum behaviour than the burying or burning of the placenta, although it has acquired new important functions for women, consistent with ideas more popular in urban areas - such as regaining one's pre-pregnancy figure after childbirth.

While the postnatal period is considered special, in particular with regard to the restrictions surrounding a woman's behaviour, it constitutes only a small part of a person's life. Moreover, this person is implicated in an intricate web of the lives of other people, who impact and transform each other through interac-

13 Neither did they distinguish clearly between kinds of malevolent winds causing different illnesses (Sp. soplas, Qu. wayras), described in ethnographies of the Andean region (see e.g. Larme 1998).

${ }^{14}$ See e.g. Arnold \& de Dios Yapita (2002: 91); Bradby \& Murphy-Lawless (2002: 43-46); Gonzales et al. (1991: 28); Suárez (1974: 45). 
tions. Sobreparto, a condition following a transgression of postpartum rules, constitutes an instance of such an impactful event.

If it can be argued that a healthy Andean body is a matter of mindful negotiation and persistence, then what about pregnancy? According to Andean medical systems, pregnancy is a hot state; childbirth, on the other hand, usually accompanied by the loss of blood, is considered cold (see e.g. Bradby 2002: 179). While this understanding was never expressed explicitly in this form by any of my research participants (although it is regularly mentioned in the anthropological literature on the Andean region), they unanimously emphasised the importance of keeping warm in the period following childbirth in order to mitigate the puerperal risks or complications (for instance, of haemorrhaging). This would involve staying inside, wearing warm clothes, especially socks and a hat (or binding the head with a scarf), drinking herbal infusions and taking certain kinds of foods - women who spoke to me frequently mentioned meaty broths and chicken or beef stews ${ }^{15}$, i.e. dishes which are eaten hot and take a long time to prepare ${ }^{16}$. These actions are taken to keep the woman warm and to ensure that the equilibrium of the body is restored. However, I would like to argue that it is significant that women I spoke to often transgress the postpartum restrictions in a manner that was deliberate, and that their consequent falling ill with sobreparto may be symptomatic of something more than just a failure to observe the rules of puerperal care.

An analysis of accounts of sobreparto I collected draws attention to a recurring feature: the traumatic experience or difficult conditions faced during pregnancy or puerperium, often relatively close to childbirth. The following bout of illness was accompanied by diagnosis and treatment involving making use of social relations with neighbours or relatives. After getting better, the problem would somehow dissipate or move into the realm of relative insignificance, into the background of women's life histories. Perhaps I am projecting my own expectations of some kind of dissolution or a closure for life events, but it often seemed as though the bouts of sobreparto had cathartic characteristics: each was violent, its outcome was uncertain, and it tested reality in an unapologetic manner. The Quechua term for sobreparto, kutipa, means "return" (Cuaresma Sánchez 2005: 216). One of my informants explained the pain felt during sobreparto in the following manner:

15 Chicken (pollo) and beef (carne) are the main kinds of meat available in Santa Cruz because of the hot climate.

${ }^{16}$ Additionally, there is a set of prohibitions which complement the postpartum proscriptions: a woman who has recently given birth should avoid exposure to cold air or drafts (referred to as aire), touching water (for instance, by doing the laundry or showering), as well as manipulating metal objects. Metal is considered to be "cold" and is thus able to cause illnesses. Those women in Bolivia who express fear of giving birth in hospital pointed to the fact that hospital rooms are very often chilly (especially in comparison to the traditional childbirth setting, where the room is purposefully well heated) and that the beds are made of metal, which adds to the general perception of hospitals as "cold" places (see e.g. Bradby 1999: 293, 296-299). 
It's like another childbirth, but worse, because you're already in so much pain after the first one. But the doctors don't know how to cure it. They give you anti-inflammatory pills, but they don't work, but you're suffering and suffering, as if you were to die... Sometimes women die...

The anguish and a considerable lack of control, coupled with the emotional turmoil of having a new baby in one's life (and, hence, new responsibilities of and towards the social network) manifests itself though the peculiar suspense in the course of life created by a postpartum illness.

In various accounts of sobreparto which I collected during my fieldwork, those episodes of illness are located within a wider framework of life circumstances as well as on a longer timeline, one which involved not only the entire pregnancy and childbirth but also the situation of the woman before she became pregnant. The stories that I heard shared some features, one of which was that there was almost invariably another person - a relative or a neighbour - who diagnosed the ailment and offered a cure, which points to the significance of the social network. At the same time, basically everyone with whom I discussed sobreparto, both men and women, insisted that biomedical doctors do not know how to cure it and only make unsuccessful attempts with anti-inflammatory pills, which informs an understanding of this condition as remaining beyond the scope of biomedicine. Furthermore, sobreparto was confined to Andean migrants, which highlights ties to highlander identity embodied in rules of pregnancy.

When I listened to the collected recordings, I realised that my interlocutors addressed my questions in ways that initially seemed slightly off-topic. I would ask: ¿Y cómo se sentía Ud. durante su embarazo?, And how did you feel during your pregnancy?, but the answers described chains of interconnected and accumulative events, ending in an illness, from which my informants were fortunate enough to recover. The stories I heard typically contained very few unprompted descriptors of emotional states - although it was not uncommon that the woman recounting her experiences had tears in her eyes or spoke in a way that was different from her normal way of talking: sometimes more quietly, sometimes in a trembling voice, sometimes looking away.

When I asked different women about their feelings at the time of pregnancy ${ }^{17}$, they gave various answers, some of which seemed more insightful than others. For instance, it was intuitively easy for me to understand replies which explicitly mentioned emotions, such as fear, joy, or anticipation, but I was startled when my question was answered with Me sentía normal, no me dolía nada, I felt normal, nothing hurt me. In the beginning, I thought that it would be fair to assume that the answers which mentioned emotions were inspired by social standards of how one is supposed to feel in a similar situation, that I was being told what they thought I wanted to hear. However, perhaps it is more significant that most women did not articulate their emotions in categories which I had been anticipating, such as

17 ¿Qué sentía Ud. durante su embarazo?, What did you feel during your pregnancy? 
joy or fear, but instead talked about their painful or pain-free bodies, and about being alone. What if, I wondered, asking about how they felt was a mistake made as the result of a wrong assumption about what emotions are? What if they were telling me about their emotions all the time, but I just failed to understand this because I expected to hear specific words? What if being lonely was not how they were, but how they felt?

\section{Sobreparto: There is more at risk than a woman's life}

As maternal and perinatal mortality rates ${ }^{18}$ in Bolivia continue to be very high by world standards, the fact that sobreparto occurs after childbirth implies additional danger. Childbirth is a precarious moment of change, especially in the suburbs of Santa Cruz where mothers (rather than the couple or the father) are expected to take care of children ${ }^{19}$. Therefore, it is not difficult to envision the potential threat an illness of the mother would pose at that special time, when the newborn baby requires constant care and attention, some of which - such as breastfeeding - are not easily delegated. Sobreparto creates a suspense in the life paths of both the woman and her infant. Perhaps it is possible to think of this suspense evoked by an illness ${ }^{20}$ as a test of one's realities, a time where the strength of one's social network is verified. People who show up to help are not necessarily the closest relatives - most of my research participants were diagnosed by a neighbour, a colleague, a friend, a sister-in-law - but they were not complete strangers either, which emphasises the significance of relying on extensive social networks created in new places, in this case by migrants to Santa $\mathrm{Cruz}^{21}$.

18 World Health Organisation defines perinatal mortality as "the number of stillbirths and deaths in the first week of life (early neonatal mortality)" (WHO 2015). The basis for calculating maternal mortality rate is the number of maternal deaths (see e.g. WHO 2014), defined as "[t]he death of a woman while pregnant or within 42 days of termination of pregnancy, irrespective of the duration and site of the pregnancy, from any cause related to or aggravated by the pregnancy or its management but not from accidental or incidental causes" (WHO 2010). According to the WHO report analyzing data from the 1980-2008 period, the Maternal Mortality Ratio (MMR) for Bolivia decreased from 547 (with 344 in urban areas and 845 in rural areas per 100,000 births) in 1980 to 439 (276-666) in 1990, to 269 (168-413) in 2000, and down to 180 (110-284) in 2008 (Hogan et al. 2010: 1616). The most recent collaborative report by WHO, UNICEF, United Nations Population Fund and The World Bank (2014) estimates it at 200 per 100,000 births. Curiously, another WHO Mortality Country Fact Sheet puts Bolivia's MMR in 2006 at 420 (WHO 2006). Yet another estimate, prepared in collaboration between the WHO and UNICEF in 1990, calculated MMR at 650 rather than 439 (WHO/UNICEF 1990).

19 This is changing, and I should say that I have met fathers who participated in child-rearing. However, the transformation is rather slow-paced.

20 See e.g. Irving (2005).

${ }^{21}$ One of my informants, Doña Gloria, was diagnosed by her sister-in-law on the phone. Doña Gloria telephoned her sister-in-law a couple of days after giving birth to her second baby and complained about the pain, chills and shivers she was experiencing. Her sister-in-law recognised the condition as sobreparto and advised drinking and washing her body with rosemary in- 
In the accounts of sobreparto I collected, women were often alone (or, perhaps more importantly, felt alone) around the time when they gave birth. After childbirth, they were visited by a relative or a neighbour, who would notice that they were unwell, diagnose the condition as well as, more often than not, offer or seek out a cure, guiding the woman out of her illness. As mentioned above, the traditional cure for sobreparto consists in drinking hot herbal infusions as well as rubbing the body with chicken or beef fat. The infusions are made using herbs considered to be hot in Andean medicine (Balladelli 1988); my informants provided different lists of ingredients for the cure for sobreparto - the only plant which appeared in most of them was romero, rosemary ${ }^{22}$. Fat, next to blood, is a vital liquid in the human body for Andean medicine and people are wary of losing it in an uncontrolled manner ${ }^{23}$

Some researchers emphasise the relationship between blood and fat and indicate that in certain areas in the Andes kharisiris are believed to steal fat as well as suck out blood (see Canessa 2000: 718; Abercrombie 1998: 64-65; Wachtel 1994: 72-74). Fat and blood have also been interpreted as idioms used to talk about social politics (Crandon-Malamud 1991). Joseph Bastien states that "[b]lood and fat empower the body: blood (Qu. yawar) is the life principle and fat $(\mathrm{Qu}$. wira) is the energy principle" (1978: 45) and that "images of fat-snatching and blood-sucking are used by Andeans to describe causes of sickness" (2003: 173). However, it is possible to argue that the part of the cure which included rubbing the body with some kind of fat or even commercially-produced ointment, such as

fusions as well as rubbing the body with fat. Doña Gloria's neighbour helped her to buy the ingredients for the cure and assisted in the treatment. While this is an example somewhat contrary to my argument (the person who recognised sobreparto in the symptoms did not visit Doña Gloria), it is clear that people who are physically near-by can help in a much more tangible manner, by bringing food or doing the laundry, thus alleviating the burden of daily life.

${ }^{22}$ In highland Bolivia, rosemary infusions are considered to be able to cure colds, general body and joint pains, maldición (curse), and pains after childbirth (Macía, García \& Vidaurre 2005: 344). In highland Ecuador, the uses of rosemary infusions included mal aire and mal viento, ailments caused by cold, malevolent winds entering the body (Cavender \& Albán 2009: 5).

${ }^{23}$ Cf. e.g. Bastien $(1978,1987)$. Although none of my informants mentioned this explicitly, Andean mythology contains a figure of the "grease stealer" (see e.g. Bradby 1999: 293). This malevolent - and, more importantly, non-human - being, usually referred to in Aymara as lik'ichiri or kharisiri, is said to act at night and steal fat from sleeping people which causes them to lose strength and even die if the condition remains untreated by a healer (Sikkink 2010: 78; Canessa 2000: 705ff.; Bastien 1978: 54). Andrew Canessa discusses the phenomenon of kharisiri in more detail. He states that rather than the (usually invisible) blood it is (visible) body fat that is considered to be the vital force in the Andean culture and that kharisiris only steal fat from people in the prime of life (which coincides with reproductive age) rather than "[c]hildren or old people [who] simply do not have enough fat" (2000: 713; see also Rivière 1991: 27, and esp. 28-29, for an excellent ethnographic comparison of lik'ichiri in various parts of the Andean zone). Other authors emphasise medical (and other) properties of another type of fat, linki, the vernix caseosa covering the newborn's skin (Platt 2002; Molinié Fioravanti 1991). It seems, however, that in the case of women who have given birth, the fear concerns the removal of their own body fat which could disappear unnoticed unless too late. 
Mentisán ${ }^{24}$, is significant beyond the curative powers of fat. The body of an ill person is massaged by another person, who makes sure that the fat or ointment is distributed in the right areas, the touch being a demonstration of unquestionable physical closeness. This mode of treatment has another significant aspect as well: being taken care of by somebody else, on the one hand, allows the woman to rest, and, on the other hand, constitutes a tangible, palpable demonstration of support on the part of one's social network.

Nonetheless, the bodily aspect of sobreparto, such as cold sweats, chills, fever, general weakness, should not be overlooked. The undeniable somatic character of sobreparto reminds us of the way the anxiety, precariousness, and incertitude are deeply grounded in the body, almost beyond control. If it is possible to think about "childbirth as the ultimate involuntary act [where women] have no choice but to surrender [their] bodies" (Figes 2008 [1998]: 28), perhaps sobreparto could be considered as an extension of this surrender into the social network, the time taken to make a decision not only to bring a child into the world but also to bring it up. And since children are not raised by individual people but within social networks ${ }^{25}$, it is important to make sure that other people are there to help the mother in that decision-making process.

It is vital to remember that all this occurs in a context where speaking about emotions (outside of the anthropologist's inquisitive questioning), just for the sake of speaking about them, is not a widely occurring practice. It is clear that so many people have a hard life that dissecting it with words may potentially have an unintended adverse effect; spilling one's guts could be interpreted as complaining or burdening others with one's problems, especially if those problems do not really have solutions. Time and time again, I would hear No me puedo quejar, I've got nothing to complain about, [lit. I can't complain], or No me gusta quejarme, I don't like complaining. But, as the experiences of migrant women in the city of Santa Cruz de la Sierra may have shown, there may be ways of feeling - and dealing with feeling - that do not need words.

\section{Conclusions}

Doña María - and many more migrant women - sees her existential condition wrapped in what she perceives as being alone. This is not to say that she ignores her children or does not recognise the fact she has relatives, friends, or neighbours. At the same time, rather than implying literal aloneness, being lonely means not having anyone who can cook, and do the laundry, someone who can relieve the burden of everyday life in difficult times. She would say: estaba solita, I was alone, implying lack of help but also loneliness rooted in only being able to rely on oneself. While there is a specific word for "lonely" in Bolivian Spanish (solitario/solitaria), it is very rarely heard. On the other hand, solito/solita, the di-

${ }^{24}$ A type of mentholated topical ointment.

25 See e.g. Barlow \& Chapin (2010); or, for an evolutionary perspective, Hrdy $(2009,1999)$. 
minutive of the word solo/sola, is used frequently to express notions of aloneness and loneliness. These states may partially overlap by definition; however, in most of the life stories shared with me, their feelings of loneliness emerged despite being surrounded by people. Loneliness, for those women, meant making potentially dangerous choices - be it touching water, going outside to bring in gas, or taking a shower - in spite of the knowledge of the possible consequences. This loneliness, despite the fact that it may look like strength and independence, embodies vulnerability and precariousness, and culminates in an episode of illness whose course asks and answers the ultimate question of the woman's position in her social world, the question of whether she is truly alone.

This paper focused on the phenomenon of sobreparto as captured in women's narratives about this particular illness. This approach allowed the location of sobreparto within a wider frame of life trajectories, exposing motifs beyond the temporarily dysfunctional body (see Mattingly \& Garro 2001; Garro 1992; Kleinman 1992). I argued that it is possible to use narratives of sobreparto as a springboard for a study of dimensions of life such as motherhood, migration, social networks, as well as emotions. Simultaneously, in addition to revealing more general themes, these narratives sometimes allowed the women themselves to make sense of their lives. By trying to explain what happened to them through their accounts of sobreparto, women articulated their personal understanding of these events (Good 1992; Becker 1997). While arriving at an explanation cannot undo what has already occurred, it offers the possibility of accepting the past and moving on (Mattingly \& Garro 2001). These individual stories of frequently difficult and challenging lives, punctuated by pregnancies, touch upon phenomena beyond the idiosyncrasies of particular life trajectories, such as modernity or understandings of gender. While motherhood remains a central aspect of womanhood, it is also characterised by inherent hardships and dangers. Whether manifesting itself as an illness or the feeling of being alone, suffering is frequently perceived to be an inescapable aspect of being a mother (Bourque \& Warren 1981). In this sense, sobreparto constitutes one of the potential risks of womanhood, further emphasised by the fact that its occurrence is inextricably related with acts of reproduction. Sobreparto exposes these issues and sheds light on their intricate complexity in the context of Andean migrants in the lowland city of Santa Cruz.

Through close analysis of an ethnographic account of sobreparto, it was possible to see the connections between the ill body, the troubled mind, and imperfect social relationships. In the Andes, the puerperal body is considered to be open (see e.g. Loza \& Álvarez 2011), and thus vulnerable to all kinds of influences. This understanding is present among Andean migrant women in Santa Cruz, although it is rarely articulated in an explicit manner. In fact, the openness of the body was expressed through narratives about failures to ensure that the body is protected during the postnatal period. However, these failures were often attributed to insufficient support on the part of one's social network, which also caused negative emotions, including feeling alone. Although never the main thread 
of the story, loneliness or feeling alone, frequently featured in women's narratives. I argued that the foregrounding of loneliness in the analysis revealed it as an existential condition, normalised through the hardships of life. Recognising the role of feeling alone in individual stories of sobreparto showed its place in the unfolding of the events that led to this postpartum illness. While I do not want to suggest that loneliness is the sole cause for sobreparto, I believe that including it in the analysis uncovers new dimensions of this phenomenon.

Sobreparto constitutes an interesting anomaly in the increasingly biomedicalised realities of Santa Cruz de la Sierra. Although it may look like an illness to biomedical personnel, it remains an important aspect of Andean understandings of well-being found among highlander migrants to the city. Recognising emotions and social relationships in the analysis of a phenomenon that is often classified as an illness enables the inclusion of wider and more complex sets of meanings into the interpretation. Central to this understanding is consideration of somatic states as expressions beyond physiology (Tapias 2006, 2015). If strong emotions can cause bodily distress, then it is also possible to look at illnesses as expressions of emotions - perhaps even too complex to be articulated with words. In such an understanding, sobreparto can be read as an intense expression of an extremely complex set of feelings and circumstances. Sobreparto may be an illness, but it is not simply an illness of the body.

\section{Acknowledgements}

I would like to thank Katarzyna Byłów-Antkowiak, Margaret Loney, Saarthak Singh as well as anonymous reviewers for their thoughtful comments and advice.

\section{References}

Abercrombie, T.A. (1998). Pathways of memory and power: Ethnography and history among an Andean people. Madison: University of Wisconsin Press.

Allen, C.J. (1982). Body and soul in Quechua thought, Journal of Latin American Lore, 8(2), 179-196.

Arnold, D.Y., Murphy-Lawless, J. et al. (2001). Hacia un modelo social del parto: Debates obstétricos interculturales en el altiplano boliviano. La Paz: ILCA.

Arnold, D.Y., de Dios Yapita, J. et al. (2002). Las wawas del Inka: Hacia la salud materna intercultural en algunas comunidades andinas. La Paz: ILCA.

Balladelli, P. P. (1988). Entre lo mágico y lo natural. Quito: Abya-Yala.

Barlow, K., Chapin B.L. (2010). The practice of mothering: An introduction, Ethos, 38(4), 324-338.

Bastien, J.W. (1978). Mountain of the condor. Metaphor and ritual in an Andean ayllu. St Paul: West Publishing Co.

Bastien, J.W. (1987). Healers of the Andes: Kallawaya herbalists and their medicinal plants. Salt Lake City: University of Utah Press.

Bastien, J.W. (2003). Sucking blood or snatching fat: Chagas' disease in Bolivia. In: J.D. Koss-Chioino, T. Leatherman, Ch. Greenway (eds.), Medical pluralism in the Andes (pp. 166-187). New York: Routledge. 
Becker, G. (1997). Disrupted lives: How people create meaning in a chaotic world. Berkeley: University of California Press.

Bourque, S.C. \& Warren, K.B. (1981). Women of the Andes: Patriarchy and social change in two Peruvian towns. Ann Arbor: University of Michigan Press.

Bradby, B. \& Murphy-Lawless, J. (2002). Reducing maternal mortality and morbidity in Bolivia: Appropriate birth practices in the formal and informal sectors of perinalatal care. La Paz: ILCA.

Bradby, B. (1999). Will I return or not?: Migrant women in Bolivia negotiate hospital birth, Women's Studies International Forum, 22(3), 287-301.

Bradby, B. (2002). Local knowledge in health: The case of Andean midwifery. In: H. Stobart \& R. Howard (eds.), Knowledge and learning in the Andes: Ethnographic perspectives (pp. 166-193). Liverpool: Liverpool University Press.

Canessa, A. (2000). Fear and loathing on the kharisiri trail: Alteritiy and identity in the Andes, Journal of the Royal Anthropological Institute, 6(4), 705-720.

Cavender, A.P. \& Albán, M. (2009). The use of magical plants by curanderos in the Ecuador highlands, Journal of Ethnobiology \& Ethnomedicine, 5(3), 1-9.

Cooley, S. (2008). Bringing body to bear in the Andes: Ethnicity, gender, and health in Highland Ecuador, Michigan Discussions in Anthropology, 17(1), 132-160.

Crandon-Malamud, L. (1991). From the fat of our souls: Social change, political process and medical pluralism in Bolivia. Berkeley: University of California Press.

Cuaresma, S., Ricardo, C. (eds.) (2005). Diccionario quechua-español-quechua. Cuzco: Gobierno Regional Cusco.

Das, V, Kleinman, A. \& Lock, M.M. (eds.) (2001). Remaking a world: violence, social suffering, and recovery. Berkeley: University of California Press.

Dibbits, I. (2003). Uno de dos: El involucramiento de los hombres en la atención de la salud perinatal, revelaciones desde Santa Rosa y Rosas Pampa, el Alto, Bolivia. La Paz: TAHIPAMU.

Figes, K. (2008) [1998]. Life after birth. London: Virago.

Frisancho Pineda, D. (1973). Medicina indígena y popular. Lima: Librería Editorial Juan Mejía Baca.

Galindo Soza, M. (2010). El progreso invisible. El Seguro Universal Materno Infantil. La Paz: Fundación Milenio.

Garro, L.C. (1992). Chronic illness and the construction on narratives. In: M.-J. DelVecchio Good, P.E. Brodwin, B.J. Good \& A. Kleinman (eds.). Pain as human experience: An anthropological perspective (pp. 100-137). Berkeley: University of California Press.

Gonzales, S.F. et al. (1991). Qualitative research on knowledge, attitudes, and practices related to women's reproductive health, Working paper no. 9. Prepared by Centro de Investigación Análisis y Estudios Socioeconómicos and MotherCare Project, Cochabamba, Bolivia.

Good, B.J. (1992). The body in pain: The making of a world of chronic pain. In: M.J. DelVecchio Good, P.E. Brodwin, B.J. Good \& A. Kleinman (eds.), Pain as human experience: An anthropological perspective (pp. 29-48). Berkeley: University of California Press.

Greenway, Ch. (1998). Hungry earth and vengeful stars: Soul loss and identity in the Peruvian Andes, Social Science EMedicine, 47(8), 993-1004.

Hogan, M.C. (ed.) (2014). Prosopis alba. South American Mestique, http:/ / eol.org/ pages/ 695196/names/common_names [accessed on: 07.10.2014].

Hrdy, S.B. (1999). Mother nature: Natural selection and the female of the species. London: Chatto \& Windus.

Hrdy, S.B. (2009). Mothers and others: The evolutionary origins of mutual understanding. Cambridge, MA: Harvard University Press. 
Irving, A. (2005). Life made strange: An essay on the re-inhabitation of bodies and landscapes. In: W. James \& D. Mills (eds.), The qualities of time: Anthropological approaches (pp. 317-329). Oxford: Berg.

Kleinman, A. (1992). Pain and resistance: The delegitimation and relegitimation of local worlds In: M.-J. DelVecchio Good, P.E. Brodwin, B.J. Good, \& A. Kleinman (eds.), Pain as human experience: An anthropological perspective (pp. 169-197), Berkeley: University of California Press.

Kleinman, A. (2006). What really matters. Living a moral life amidst uncertainty and danger. New York: Oxford University Press.

Larme, A.C. \& Leatherman T. (2003). Why sobreparto? Women's work, health and reproduction in two districts of southern Peru. In: J.D. Koss-Chioino, T. Leatherman, Ch. Greenway (eds.), Medical pluralism in the Andes (pp. 191-208). New York: Routledge.

Larme, A.C. (1993). Work, reproduction, and health in two Andean communities (Department of Puno, Peru). Working Paper No. 5. Production, storage, and exchange project. University of North Carolina Department of Anthropology, Chapel Hill, NC.

Larme, A.C. (1998). Environment, vulnerability and gender in Andean ethnomedicine, Social Science \& Medicine, 47(8), 1005-1015.

Leatherman, T. (1998). Changing biocultural perspectives on health in the Andes. Social Science \& Medicine, 47(8), 1031-1041.

Lira, J.A. (1985). Medicina andina. Farmacopoea y ritual. Cusco: Centro de Estudios Rurales Andinos.

Loza, C.B. \& Álvarez, W. (2011). Sobreparto de la mujer indígena, saberes y prácticas para reducir la muerte materna. La Paz: INBOMETRAKA.

Luerssen, J.S. (1993). Illness and household reproduction in a highly monetized rural economy: A case from the Southern Peruvian Highlands, Journal of Anthropological Research, 49(3), 255-281.

Macía, M.J., García, E. \& Vidaurre, P.J. (2005). An ethnobotanical survey of medicinal plants commercialized in the markets of La Paz and El Alto, Bolivia, Journal of Ethnopharmacology, 97, 337-350.

Mattingly, Ch. \& Garro, L.C. (2001). Narrative as construct and construction. In: Ch. Mattingly \& L.C. Garro (eds.), Narrative and the cultural construction of illness and healing (pp. 1-49). Berkeley: University of California Press.

Miles, A. \& Leatherman, T. (2003). Perspectives on medical anthropology in the Andes. In: J.D. Koss-Chioino, T. Leatherman \& Ch. Greenway (eds.), Medical pluralism in the Andes (pp. 3-15), New York: Routledge.

Ministerio de Salud y Deportes. (2006). Protocolos de de atención materna y neonatal culturalmente adecuados. La Paz: Ministerio de Salud y Deportes/Organización Panamericana de Salud - Organización Mundial de Salud/Causananchispaj.

Molinié Fioravanti, A. (1991). Sebo bueno, indio muerto: La estructura de una creencia andina, Bulletin de l'Institut d'Études Andines, 20(1), 79-92.

Morgan, L. (1997). Imagining the unborn in the Ecuadoran Andes, Feminist Studies, 23(2), 322-350.

Murphy-Lawless, J. (1998). Reading birth and death. A history of obstetric thinking. Cork: Cork University Press.

Plath, O. (1981). Folclor médico chileno: Antropología y salud. Santiago de Chile: Editorial Grijalbo.

Platt, T. (1997). The sound of light: Emergent communication through Quechua shamanic dialogue. In: R. Howard-Malverde (ed.), Creating context in Andean cultures (pp. 196-226). New York: Oxford University Press.

Platt, T. (2002). El feto agresivo: Parto, formación de la persona y mitohistoria en los Andes, Estudios Atacameños, 22, 127-155. 
Platt, T. (2013). Care and carelessness in rural Bolivia: Silence and emotion in Quechua childbirth testimonies, Bulletin de l'Institut Français d'Études Andines, 42(3), 333-351.

Rivière, G. (1991). Lik'ichiri y kharisiri... A propósito de las representaciones del 'otro' en la sociedad Aymara, Bulletin de l'Institut d'Études Andines, 20(1), 23-40.

Sikkink, L. (2010). New cures, old medicines: Women and the commercialization of traditional medicine in Bolivia. Belmont: Wadsworth/Cencage Learning.

Suárez, M.M. (1974). Etiology, hunger, and folk diseased in the Venezuelan Andes, Journal of Anthropological Research, 30(1), 41-54.

Tapias, M. (2006). Emotions and the intergenerational embodiment of social suffering in rural Bolivia, Medical Anthropology Quarterly, 20(3), 399-415.

Tapias, M. (2015). Embodied protests: Emotions and women's health in Bolivia. Urbana: University of Illinois Press.

Tousignant, M. (1989). Sadness, depression and social reciprocity in Higland Ecuador, Social Science \& Medicine, 28(9), 899-904.

Wachtel, N. (1994). Gods and vampires: Return to Chipaya, transl. by C. Volk. Chicago: University of Chicago Press.

WHO, UNICEF, United Nations Population Fund \& The World Bank (2014). Trends in maternal mortality: 1990 to 2013. Geneva: WHO.

WHO (2006). "Mortality country fact sheet 2006: Bolivia", http:/ /www.who.int/ whosis/ mort/profiles/mort_amro_bol_bolivia.pdf [accessed on: 13.12.2011].

WHO (2010). International statistical classification of diseases and related health problems, tenth revision. Vol. 1: Tabular list. Vol. 2: Instruction manual. Geneva: WHO.

WHO (2014). Trends in maternal mortality: 1990 to 2013. Estimates by WHO, UNICEF, UNFPA, The World Bank and the United Nations Population Division, http:/ / apps.who. int/iris/bitstream/10665/112682/2/9789241507226_eng.pdf?ua=1 [accessed on: 25.04.2015].

WHO (2015). "Maternal, newborn, child and adolescent health: Maternal and perinatal health", http://www.who.int/maternal_child_adolescent/topics/maternal/maternal_perinatal/en/ [accessed on: 04.04.2015].

WHO/UNICEF (1990). “Revised 1990 estimates of maternal mortality: A new approach by WHO and UNICEF", http://whqlibdoc.who.int/hq/1996/WHO_FRH_MSM_96. 11.pdf [accessed on: 13.12.2011].

Yon Leau, C. (2000). Hablan las mujeres andinas: Preferencias reproductivas y anticoncepción. Lima: Movimiento Manuela Ramos.

\section{SUMMARY}

Sobreparto and the lonely childbirth: Postpartum illness and embodiment of emotions among Andean migrants in Santa Cruz de la Sierra, Bolivia

The goal of this paper is to analyse the phenomenon of sobreparto, a traditionally Andean postpartum condition, among Andean migrants to the lowland city of Santa Cruz de la Sierra, Bolivia. Although matters of maternal health have usually be examined through the lens of traditional Andean understandings of the body, health, and illness, it is also analytically worthwhile to foreground the social and emotional dimensions of this postpartum illness. This is especially important given the fact that most research participants emphasised that biomedical doctors do not know how to cure sobreparto. In particular, it is especially productive to consider it as a lens for wider, not necessarily medical, processes at work in migrant women's lives, such as motherhood and womanhood, emotions and sociality, or the biomedicalisation of pregnancy and childbirth. While narrating their indi- 
vidual experiences of sobreparto, female migrants in Santa Cruz pointed to aspects of women's lives beyond the episodes of illness, revealing the complex landscapes of their everyday existence. Using migrants' accounts of their experiences of childbirth, I argue that sobreparto may be read as a way of dealing with the feeling of loneliness within a weakened social network, so common among migrants to urban areas. Furthermore, this postpartum illness becomes an emblem of ethnicity for the Andean migrants in the increasingly biomedicalised landscape of childbirth in Santa Cruz, enabling them to articulate an embodied commentary on the social realities they experience.

Keywords: sobreparto, postpartum illness, childbirth, embodiment of emotions, Santa Cruz de la Sierra, Bolivia 